Supplementary Material 1 for Paper

Anammox, denitrification and dissimilatory nitrate reduction to ammonium in the East China Sea sediment

G. D. Song ${ }^{1}$, S. M. Liu ${ }^{1}$, H. Marchant ${ }^{2}$, M. M. M. Kuypers ${ }^{2}$, G. Lavik ${ }^{2}$

[1]\{Key Laboratory of Marine Chemistry Theory and Technology, Ministry of Education, College of Chemistry and Chemical Engineering, Ocean University of China, 238 Songling Road, 266100 Qingdao, China\}

[2]\{Department of Biogeochemistry, Max Planck Institute for Marine Microbiology, Celsiusstrasse 1 D-28359 Bremen, Germany\}

Correspondence to: S. M. Liu (sumeiliu@,ouc.edu.cn) 

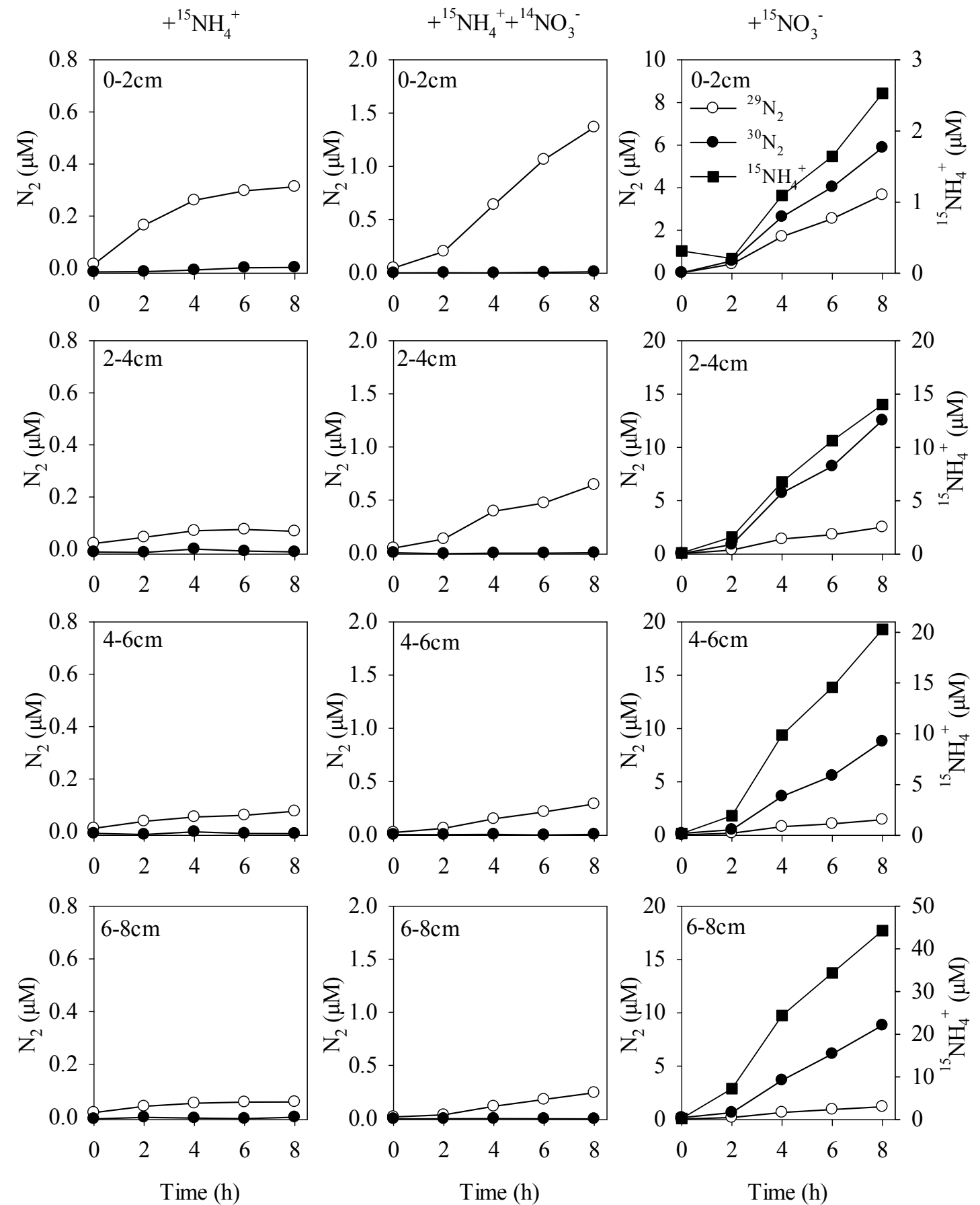

Fig. S1 Production of ${ }^{29} \mathrm{~N}_{2},{ }^{30} \mathrm{~N}_{2}$ and ${ }^{15} \mathrm{NH}_{4}{ }^{+}$against time in slurry incubation at DH31. 

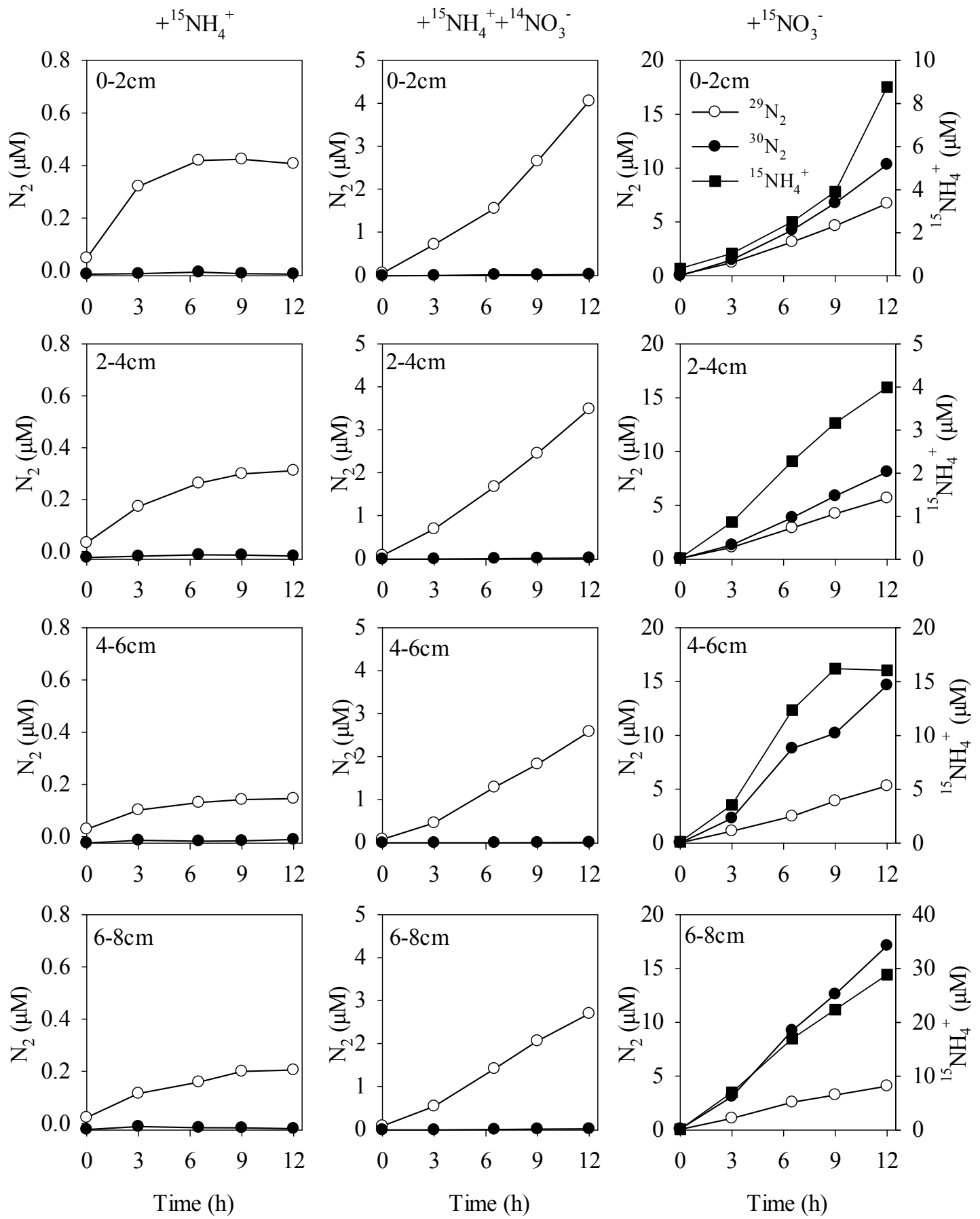

Fig. S2 Similar to Fig. S1 but at DHa2. 

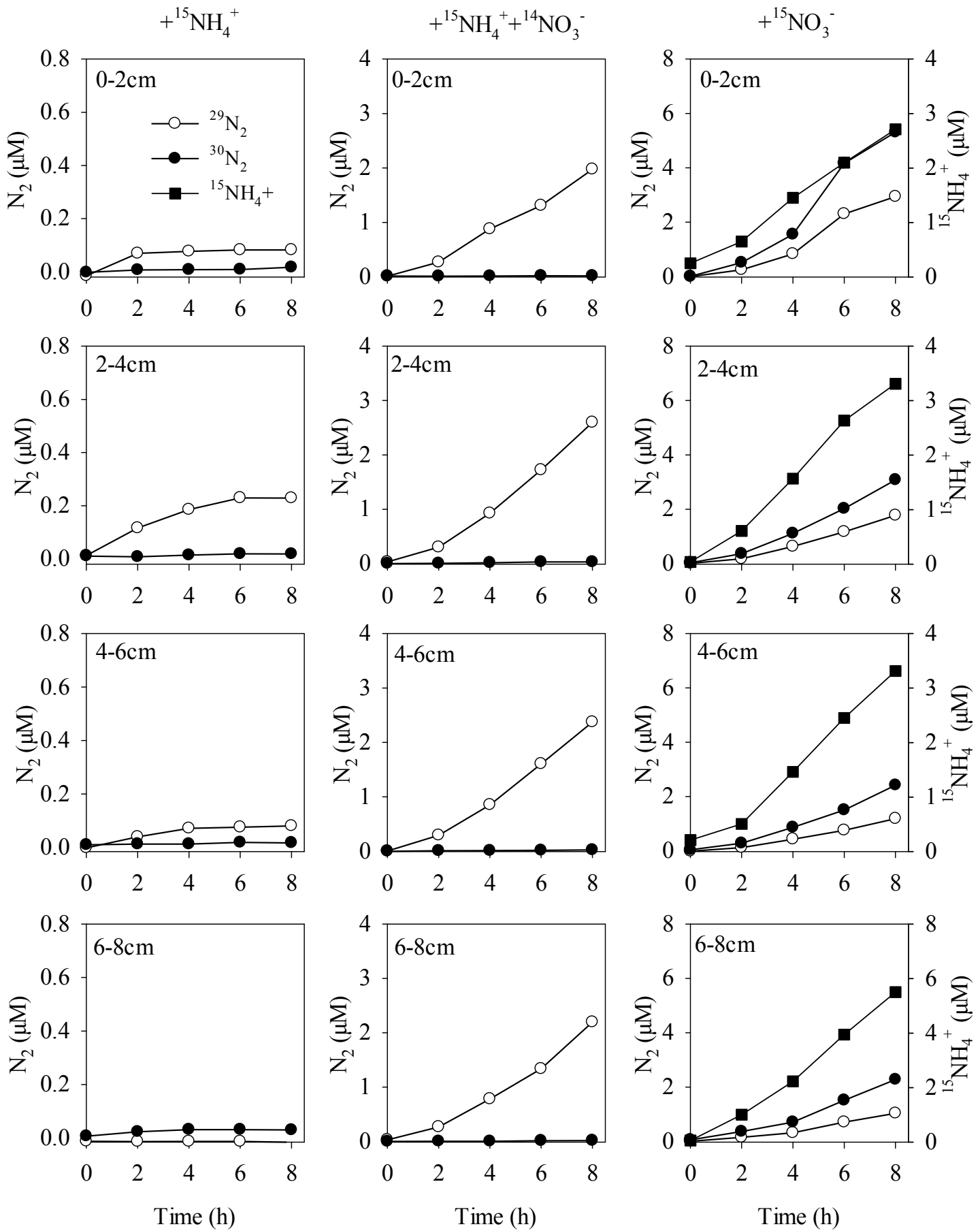

Fig. S3 Similar to Fig. S1 but at DH53.

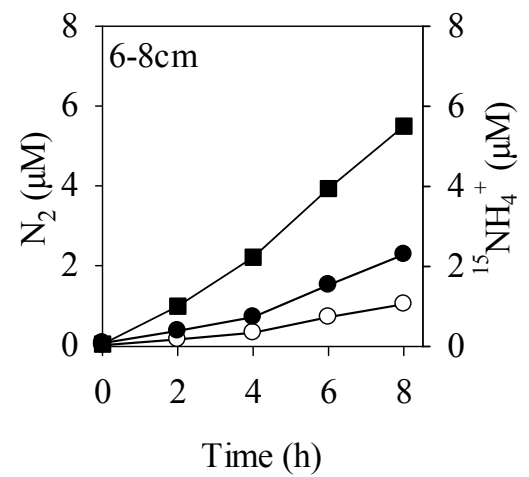



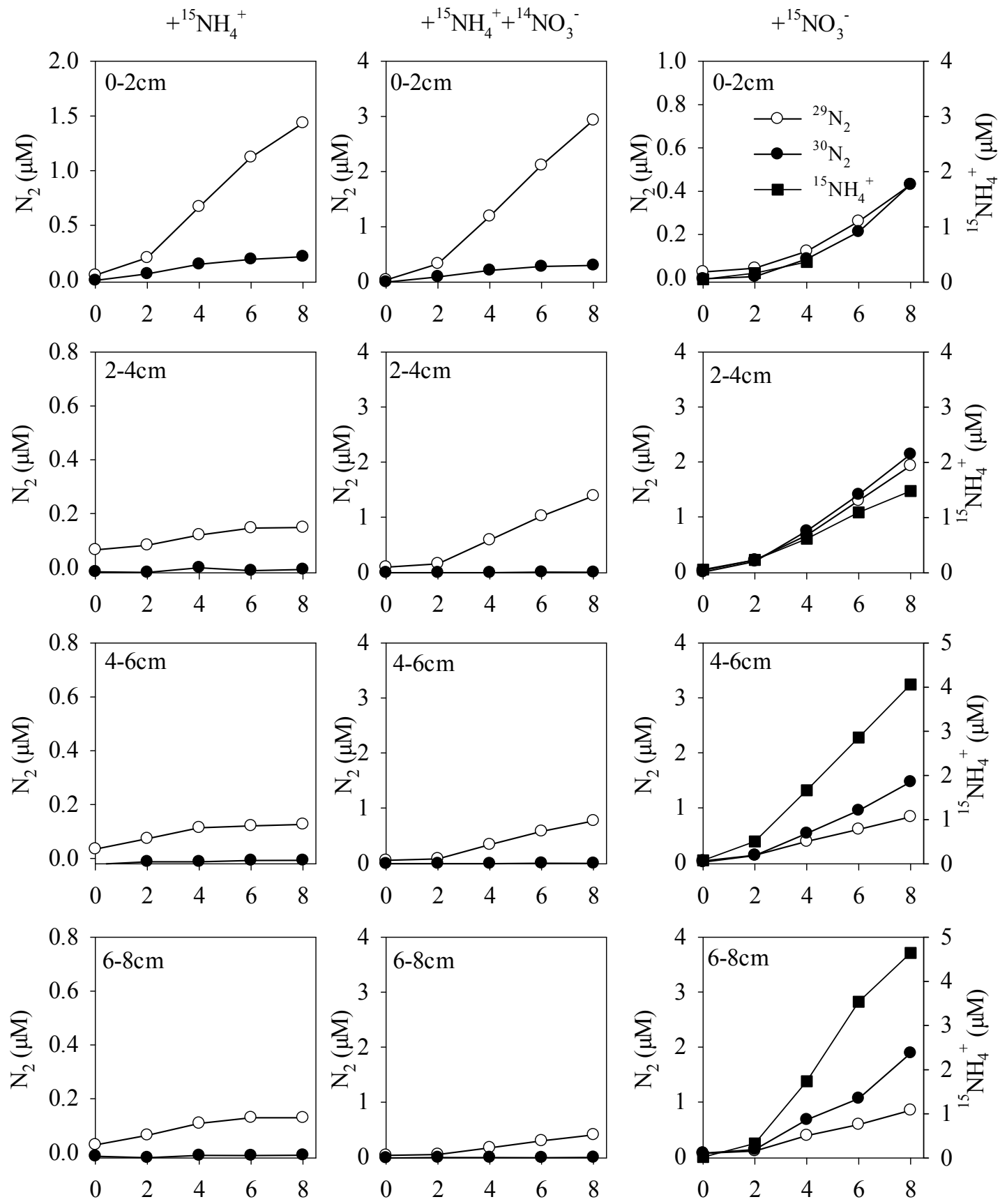

Time (h)

Time (h)

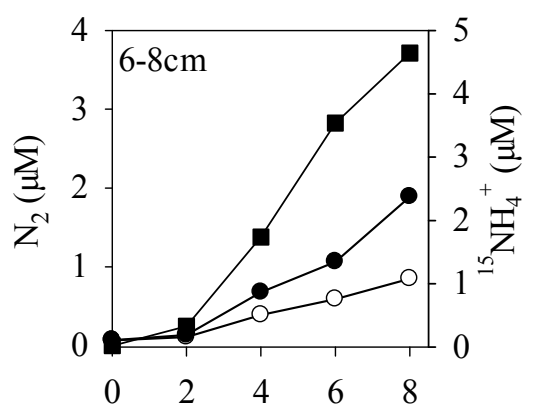

Fig. S4 Similar to Fig. S1 but at DH55. 

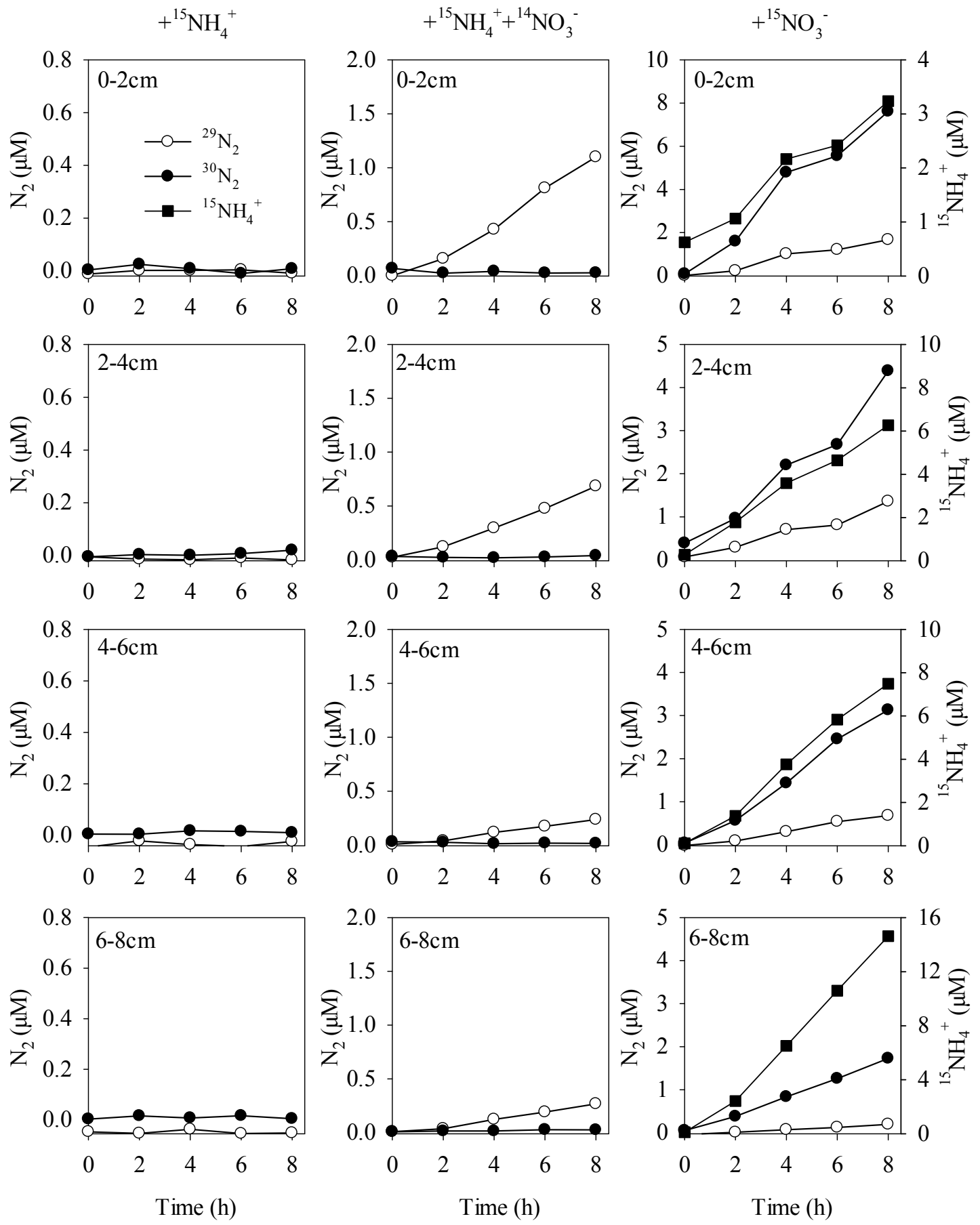

Fig. S5 Similar to Fig. S1 but at DH15. 
Supplementary Material 2 for Paper

\section{Anammox, denitrification and dissimilatory nitrate reduction to ammonium in the East China Sea sediment}

G. D. Song ${ }^{1}$, S. M. Liu ${ }^{1}$, H. Marchant ${ }^{2}$, M. M. M. Kuypers ${ }^{2}$, G. Lavik ${ }^{2}$

[1]\{Key Laboratory of Marine Chemistry Theory and Technology, Ministry of Education, College of Chemistry and Chemical Engineering, Ocean University of China, 238 Songling Road, 266100 Qingdao, China\}

[2]\{Department of Biogeochemistry, Max Planck Institute for Marine Microbiology, Celsiusstrasse 1 D-28359 Bremen, Germany

Correspondence to: S. M. Liu (sumeiliu@ouc.edu.cn) 


\section{Supplementary discussion about the influence of nitrate release on anammox rate calculation.}

The potential rates of anammox could be calculated from the production of ${ }^{29} \mathrm{~N}_{2}$ and ${ }^{30} \mathrm{~N}_{2}$ and the labeling ${ }^{15} \mathrm{NO}_{3}{ }^{-}$fraction $\left(\mathrm{F}_{\mathrm{N}}\right)$ in the slurry incubation with the calculation procedure of Thamdrup and Dalsgaard (2002) as was shown in equation (2) in the text. If nitrate release occurred, then we could use equation (4) to calculate the derived ${ }^{15} \mathrm{NO}_{3}{ }^{-}$fraction $\left(\mathrm{F}_{\mathrm{N}}{ }^{*}\right)$.

$$
\begin{aligned}
& A_{\left(E_{-} \text {Denit }\right)}=\left[P_{29}-2 \times\left(1 / F_{N}-1\right) \times P_{30}\right] / F_{N} \\
& F_{N}^{*}=\frac{\left(P_{29}+2 \times P_{30}\right)-\sqrt{\left(P_{29}+2 \times P_{30}\right)^{2}-8 \times \mathrm{A}_{\left(E_{-} \_ \text {Amox }\right)} \times P_{30}}}{2 \times \mathrm{A}_{\left(\mathrm{E}_{-} \text {Amox }\right)}}
\end{aligned}
$$

Where, $A_{\left(E_{-} \text {Denit }\right)}$ denoted the potential rate anammox in E_Denit. $\mathrm{P}_{29}$ and $\mathrm{P}_{30}$ were the production rate of ${ }^{29} \mathrm{~N}_{2}$ and ${ }^{30} \mathrm{~N}_{2}$ in E_Denit, which could be obtained by the linear regression of the $\mathrm{N}_{2}$ isotope concentration against time.

This first order derivative of equation (2) could be written as,

$$
\frac{d A_{\left(E_{-} \text {Denit }\right)}}{d F_{N}}=\frac{4 \times P_{30}-\left(P_{29}+2 P_{30}\right) \times F_{N}}{F_{N}^{3}}=\frac{4-(r 29+2) \times F_{N}}{F_{N}^{3} / P_{30}}
$$

Where, r29= $\mathrm{P}_{29} / \mathrm{P}_{30}$. Because $0<\mathrm{F}_{\mathrm{N}}<1$, if $0<F_{N}<4 /(r 29+2), \frac{d A_{\left(E_{-} \text {Denit }\right)}}{d F_{N}}$ would be a positive value and equation (2) would be an increasing function with $\mathrm{F}_{\mathrm{N}}$. In our study, all the measured $\mathrm{r} 29<2$, thus $4 /(\mathrm{r} 29+2)>1$, therefore when $0<\mathrm{F}_{\mathrm{N}}<1$, the anammox rate in E_Denit would also decrease with the decreasing of $F_{N}$. Thus, anammox rate would be overestimated if nitrate release was not considered according to equation (2). If nitrate release was very significant and led to the mismatch of potential anammox rate in E_Amox and E_Denit, then $\left(P_{29}+2 \times P_{30}\right)^{2}-8 \times \mathrm{A}_{\left(\mathrm{E}_{-} \mathrm{Amox}\right)} \times P_{30}$ could probably be less than 0 , meaning that equation (4) could not be solved successfully. Maybe this was the case for 4 samples in our study; in these cases we recommended the anammox rates from E_Amox as the actual rates, as here nitrate release would have no effect. Besides, in another 4 
samples, calculated $\mathrm{F}_{\mathrm{N}}{ }^{*}$ was higher than $\mathrm{F}_{\mathrm{N}}$, even more than $100 \%$, these maybe caused by the sediment heterogeneity. In these cases, we used the original $F_{N}$ to calculate $\mathrm{A}_{\mathrm{E}_{-} \text {Denit. }}$ However, excluding the four samples that we could not calculate $\mathrm{F}_{\mathrm{N}}{ }^{*}$, all other anammox rates from the two experiments were consistent (Fig. 8a in the text). 